\title{
Investing in the commons: transient welfare creates incentives despite open access
}

\author{
$\underline{\text { Jacob P. Ziegler }}^{1}$, Sunny L. Jardine ${ }^{2}$, Stuart E. Jones $^{3}$, Brett T. van Poorten $^{4}$, Marco A. Janssen $^{5,6}$ and Christopher T. Solomon $^{7}$
}

\begin{abstract}
Local users may invest in managing common pool resources, thereby promoting social and ecological resilience. Institutional or economic limits on access are regarded as essential preconditions for incentivizing local investments, but we show that investment incentives can exist even under open access. We modeled a recreational harvest fishery in which local or centralized managers invest in fish stocking to maximize social welfare. Although classic open access dissipation of rents occurs at equilibrium, the sluggish response of fishing effort to changing conditions allows welfare to accrue in transition to equilibrium. This transient welfare creates persistent incentives to invest. Empirical observations showed that stocking by local collective action groups occurred at rates similar to model-predicted optima, while centralized stocking occurred at rates greater than predicted optima. Our results emphasize the potential benefits of local involvement in managing the commons, even under conditions that were previously thought to preclude effective collective action.
\end{abstract}

Key Words: angler; collective action; common pool resource; fish stocking; fishery; lake association; open access; polycentric governance; social-ecological system

\section{INTRODUCTION}

Some of the greatest successes - and most formidable remaining challenges - in environmental governance center on common pool resources such as forests and fisheries. Early thinking about managing common pool resources to avoid overuse focused on establishing centralized government control or private property rights (Scott 1955, Hardin 1968). More recently, researchers have demonstrated that local resource users can take voluntary collective action to sustainably manage these resources (Berkes et al. 1989, Ostrom 1990). This local collective action, set within broader polycentric governance arrangements, can promote social-ecological resilience to resource collapse (Feeny et al. 1990, Dietzet al. 2003, Carpenter and Brock 2004, Gutiérrez et al. 2011).

Under limited access, users may have incentives to invest in improving or maintaining the resource when those investments yield benefits greater than those that would result from not investing (Ostrom 1998). Under open access, in contrast, incentives for investment are reduced or eliminated because any returns are dissipated as improvements in the resource draw more users into the system (Smith 1968). For this reason, previous work on enabling conditions for collective action has focused on cases where resource users hold the property right of exclusion, via either government- or community-defined rules, and so can limit access (Berkes et al. 1989, Feeny et al. 1990, Ostrom 1990, McGinnis 1999, Dietz et al. 2003).

Most recreational fisheries in North America are open access common pool resources because the license fee for recreational anglers is low and the number of licenses available is unlimited (Post 2013, Arlinghaus et al. 2019). Yet investments in voluntary fish stocking by local anglers occurs widely throughout North America and in open access fisheries around the world (Korth and Klessig 1990, Lorenzen et al. 1998, Johnson et al. 2009). This observation, other recent empirical evidence that shared resources can sometimes be governed successfully without limited access or clear boundary rules (Baggio et al. 2016, Moritz et al. 2018), and the imperiled state of recreational fisheries globally (Post 2013, Arlinghaus et al. 2019) all suggest a need to re-examine theory about investments in open access common pool resources.

To explore investments in open access common pool resources, we adapted a classic model of fishery dynamics (Smith 1968), which we parameterized and tested with empirical data. We demonstrate a previously unrecognized mechanism that can create incentives for investments in common pool resources, even under the widespread open access conditions that were previously thought to eliminate such incentives.

\section{METHODS}

\section{Model overview}

We adapted a classic open access fishery model (Smith 1968) to describe a lake recreational fishery in which either a local or a centralized manager seeks to maximize welfare to individuals in their purview by choosing the rate at which to invest in stocking fish through time. The local manager is a collective action organization composed of lakeshore residents, and focuses on maximizing welfare only for resident anglers. The centralized manager is a state fisheries agency, and so its definition of welfare includes resident anglers but also roving anglers who reside elsewhere and visit the lake to fish. We focused on the conditions that incentivize investments in a common pool resource by local and centralized managers under open access; we did not explore the emergence of local collective action, which has been addressed extensively elsewhere (Ostrom 1990). We provide a complete description of the model including equations and parameter values in Appendix 1, and solve analytically for the optimal stocking rate in Appendix 2.

\footnotetext{
${ }^{1}$ Department of Natural Resource Sciences, McGill University, ${ }^{2}$ School of Marine and Environmental Affairs, University of Washington, ${ }^{3}$ Department of Biological Sciences, University of Notre Dame, ${ }^{4}$ Simon Fraser University, ${ }^{5}$ School of Sustainability, Arizona State University, ${ }^{6}$ School of Complex Adaptive Systems, Arizona State University, ${ }^{7}$ Cary Institute of Ecosystem Studies
} 
Resident and rover fishing effort in our model respond positively and sluggishly to fishing quality (Smith 1968), defined separately for residents and rovers as the current average net benefits of catch less the access costs. Access costs influence effort allocation in fisheries, and are an important axis of heterogeneity between angler groups in our model because residents have lower marginal access costs than rovers (Clawson 1959, Brown and Mendelsohn 1984). Our effort model follows bioeconomic theory for open access fisheries, which assumes that effort responds myopically to current average net benefits (Gordon 1954, Smith 1968, McConnell and Sutinen 1979, Anderson 1993). Although myopic behavior is a standard assumption in models of aggregate fishing effort in open access, alternative models of capital investments in open access have been developed based on the assumption that resource users have rational expectations and make participation decisions based on the entire future path of net benefits (e.g., Berck and Perloff 1984, McKelvey 1985). However, our setting is characterized by relatively low capital requirements for participation, which suggests that the assumption of myopic behavior is a better representation of the participation decision. Sluggishness in models of fishing effort is typically understood to represent delays in response times due to the need to divest capital out of one fishery and invest that capital in an alternative use. For recreational angling where investments in participation are minimal, a better motivator for sluggishness is the difference between expected and realized utility. For example, with a model of adaptive expectations, where individuals formulate their expectations based on information from the past, anglers will systematically over-predict their utility from fishing if the fish stock level is declining over time, leading to a sluggish exit even when utility is negative. Adaptive expectations is a reasonable assumption in our scenario where the fish stock levels are unobservable by anglers, and is the most commonly employed assumption in empirical models of fishing location choice where backward rolling averages of revenue are used to define expected revenues from fishing (Smith and Wilen 2003). In keeping with the open access nature of most recreational fisheries in North America, we assume that there are no formal or informal institutions that limit effort.

Our model is generalizable to any harvest-oriented recreational fishery, but in this analysis we parameterized it from the literature to represent the open access fishery for walleye (Sander vitreus) in lakes of northern Wisconsin, USA. In this region, recreational fisheries are socially, economically, and ecologically important and have been studied extensively (Liu et al. 2007). Walleye is the most commonly fished and stocked species; it is fished primarily for harvest but is released voluntarily at low rates (Fenton et al. 1996, Beard et al. 2003, Gaeta et al. 2013). Collective action organizations in this region often invest in stocking walleye in their lakes, even though maintaining and enhancing fisheries is only one of many factors that led to the initial formation of those organizations (Gabriel and Lancaster 2004). As in northern Wisconsin, walleye and its congeners support important recreational fisheries across northern North America and Eurasia.

We solved the model numerically to find the optimal stocking rates through time that maximized the management objective under either local or centralized management, and identified the conditions that created incentives for stocking investments.

\section{Comparison to empirical data}

As a check on the validity and utility of our model structure, we examined whether model-predicted rates of local and centralized stocking, and model-predicted fish abundance, were similar to observed data from a set of lakes in the region for which the model was parameterized. Data on local and centralized stocking, resident and roving angler effort, and (in most cases) walleye abundance were available for 46 lakes in Vilas and Oneida Counties, northern Wisconsin. All of these lakes have public boat launches that are maintained by the state. For each of these lakes, we parameterized a version of our model that included lakespecific estimates of resident and roving angler effort, roving angler access costs and willingness to pay for harvest, and catchability. We then asked, without fitting or tuning the model, whether lake-specific model predictions of stocking rates and walleye abundance were similar to the observed data.

\section{RESULTS}

Local users had clear incentives to invest in the fishery despite open access (Fig. 1). The optimal equilibrium stocking rate for local managers was positive as long as resident anglers were present, and it was positively related to the contribution of resident anglers to total effort (Fig. 1A). The contributions of resident and roving anglers at equilibrium depended on initial conditions because high initial effort by one group reduced the catch benefits available to the other group (Appendix 1, Fig. A1.1). Local investments in stocking led to gains in welfare for local residents, and also for rovers (Fig. 1B, Appendix 3). The gains for residents were largest when residents comprised most of the equilibrium angling effort but were positive even when they were rare relative to rovers.

Incentives for local investments arose from the transient welfare that accrued during the transition to equilibrium (Fig. 2A). We illustrate this result with a simulation initialized at the open access, no-stocking equilibrium; this represents the least favorable conditions for the emergence of investment incentives, and the results hold for other initializations, such as a "pristine" state with low fishing effort and a fish stock near carrying capacity (Appendix 4, Fig. A4.1). Our model, like classic open access fisheries models, shows that rents are dissipated at equilibrium (Fig. 2A). Nonetheless, substantial gains in welfare occur during the transition to equilibrium as higher catch rates draw effort into the system. These welfare gains are followed by welfare losses as catch rates decline and effort begins to leave the system, but the gains outweigh the losses. Furthermore, switching at any time from the optimal stocking path to a no-stocking alternative results in sharp reductions in welfare, and so is disincentivized (Fig. 2A, dashed line). Incentives for local investments did not depend on institutional limits on open access (which were absent from our model) or on high access costs for roving anglers relative to residents (Fig. 1), and key results from our model hold if marginal costs of effort are increasing (Appendix 5).

Transient welfare also created incentives for a centralized manager to invest in the fishery (Fig. 1, Fig. 2B). The centralized manager's definition of welfare included roving as well as resident anglers; thus, the optimal stocking rate was higher under centralized management (Fig. 1A) and the gain in welfare from stocking was larger (Fig. 1B). These increases arose partly from rovers' high access costs and thus the high value that they placed on harvest, 
relative to residents (Appendix 3), but were present even when we set the value of harvest equal for rovers and residents (dashed yellow line in Fig. 1A). The centralized manager's more inclusive definition of welfare also meant that, unlike under local management, the optimal stocking rate and the welfare gains from stocking were negatively related to the contribution of resident anglers to total equilibrium effort (Fig. 1A, 1B). When residents comprised most of the angling effort, centralized and local management led to similar stocking rates and welfare gains.

Fig. 1. (A) Optimal stocking rate and (B) welfare gain (present value of net benefits [PVNB]) from stocking relative to a nostocking baseline, under local management by a collective action organization of lakeshore residents or centralized management by a government agency. The optimal investment and the resulting welfare gain depend on the proportion of total equilibrium angling effort that is comprised of resident anglers (x-axis). The solid line shows the default condition when access costs are higher for roving anglers than for resident anglers; the dashed line shows the case when access costs are equal.
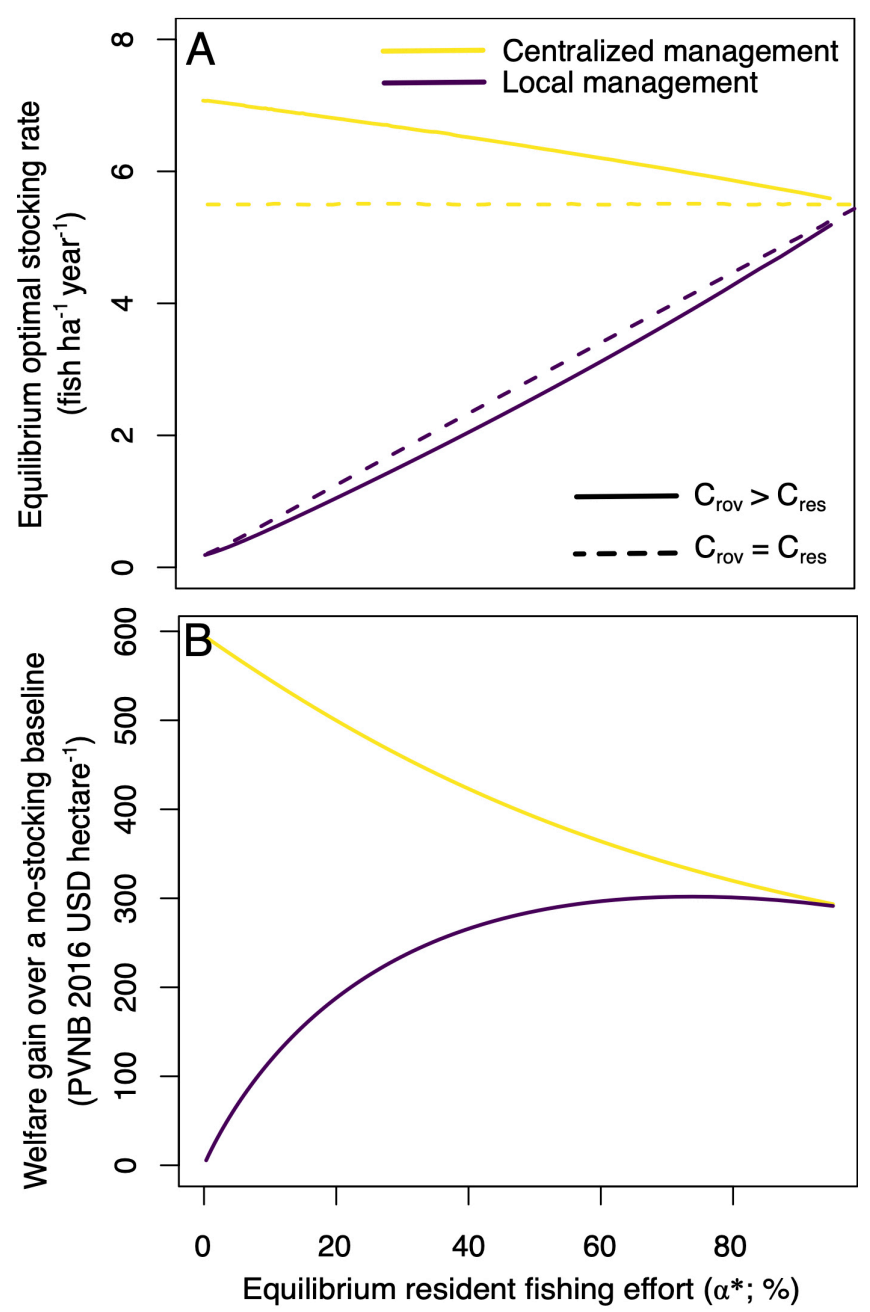

Fig. 2. Welfare accrues during the transition to equilibrium, even though rents are dissipated at equilibrium, under (A) local management and (B) centralized management. Starting from the no-stocking open access equilibrium, we considered three scenarios. First, if there is no stocking (grey line), the system remains at the open access equilibrium and net benefits are zero over the entire time horizon. Second, if stocking follows the welfare-maximizing optimal path (solid line), net benefits are initially negative because costs but not benefits of stocking have been realized; become positive and then negative again as effort responds sluggishly to changes in the fishery; and finally reequilibrate at the open access equilibrium. Third, switching from the optimal stocking path to no stocking (dashed line) does not yield gains in welfare, regardless of the time point at which the switch is made, because ceasing to stock produces negative net benefits for anglers as effort declines and the system transitions to equilibrium.

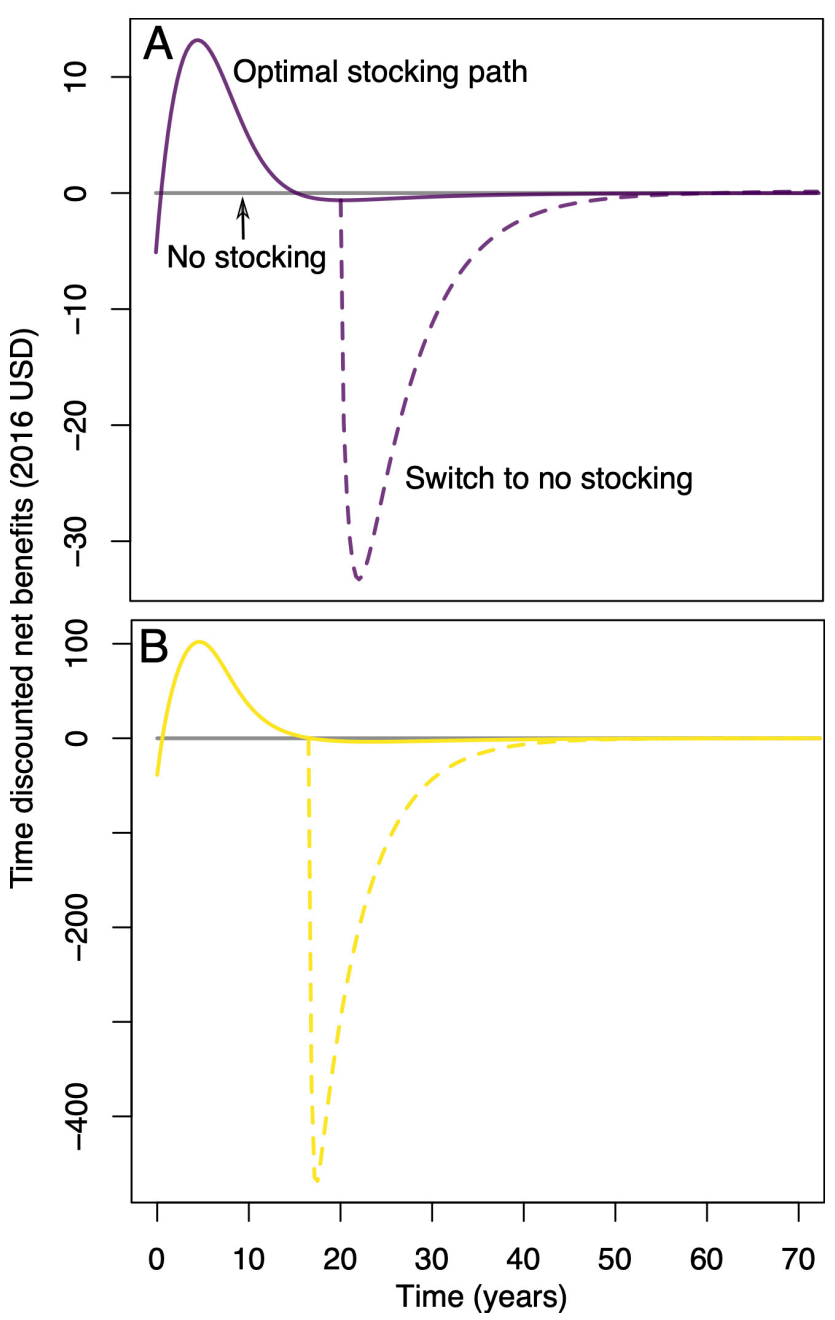


Fig. 3. (A) Observed stocking rates of walleye, and the proportion of the stocking that is conducted by centralized, rather than local, management in 46 lakes in northern Wisconsin, USA. (B) As predicted by the model, higher contributions by local resident anglers to total angling effort were positively associated with observed stocking by local managers $(p=0.004)$ and negatively associated with observed stocking by the centralized manager $(p=0.04)$. (C) Observed stocking rates by local management organizations were greater than, but close to, the optimal stocking rates predicted by our model (mean difference 1.9 fish ha $^{-1}$ year ${ }^{-1}$, paired $t$ test, $p<$ 0.001 ), while those by centralized management were generally much greater than predicted optima (mean difference 27 fish ha ${ }^{-1}$ year $\left.^{-1}, p<0.001\right)$. Walleye densities were similar to model predicted values on average $(p=0.8$ and $p=0.7$ for local and centralized management, respectively). Circles show the differences between observed and predicted values for individual lakes; these are positioned along the $y$-axis to help visualize the kernel density estimates of the frequency distributions, which are shown with lines. The two plots share the same x-axis scale (indicated along bottom of the bottom plot) but have different x-axis units (indicated in the title of each plot).
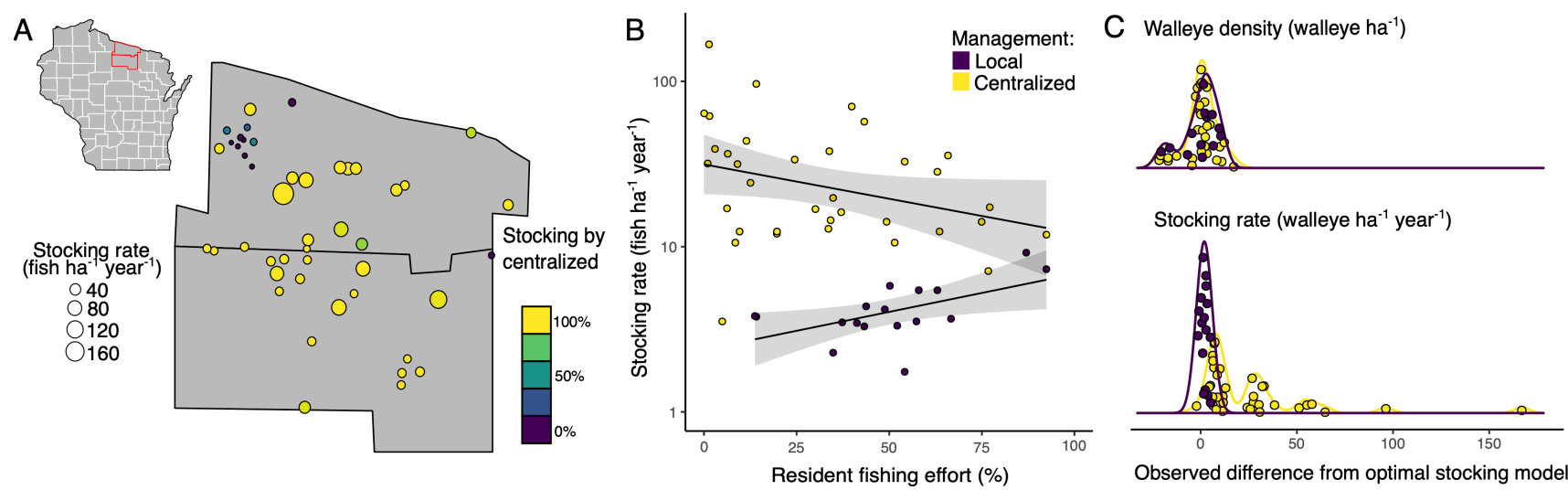

Empirical observations showed patterns similar to those predicted by our model (Fig. 3). Stocking of walleye by local lake organizations and the centralized management agency varied widely, in both absolute and relative terms (Fig. 3A). Local lake organizations stocked at lower rates than the centralized agency $\left(\right.$ mean $=4$ and 31 fish $^{-1}$ year $^{-1}$, respectively, $\mathrm{t}_{38}=5.2, p<0.001$ ). Local stocking was positively related, and centralized stocking was negatively related, to the proportion of residents in the angler pool, and stocking rates under the two management regimes were similar in lakes where residents comprised $>80 \%$ of angling effort (Fig. 3B; compare to solid lines in Fig. 1A). Quantitatively, the model predicted local stocking rates reasonably accurately but under-predicted centralized stocking rates (Fig. 3C). Empirical observations of walleye density also agreed well with model predictions, for both local and centralized stocking (Fig. 3C); this makes sense despite the high empirical centralized stocking rates because equilibrium fish density under open access is independent of stocking rate and depends only on parameters for which we had lake-specific empirical estimates (Appendix 1, Eq. A1.8, Table A1.1).

\section{DISCUSSION}

Our results demonstrate that transient dynamics create incentives to invest in improving common pool resources, even under open access. Economists have considered transient welfare in dynamic models as an incentive to invest in exploitative capital such as fishing boats (Smith 1968, Berck and Perloff 1984, McKelvey 1985, Sanchirico and Wilen 1999, Wilen 2018), but we show it can also create incentives to invest in improving the resource and that those incentives can persist even when net benefits are driven to zero in equilibrium. Moritz et al. (2018) hypothesized that ecological dynamics such as disturbance regimes that keep a system in transition to equilibrium can prevent overuse of open access common pool resources. Our results provide a mechanistic understanding of the importance of transitional periods for unique investment incentives for open access common pool resources that can drive collective-action decisions and equilibrium outcomes.

The model predicts positive stocking rates at equilibrium (Fig. 1), even while net benefits to anglers are driven to zero (Fig. 2). Together these results imply that it is optimal to operate at a loss, paying for stocking even when anglers receive no net benefits from their harvest of stocked fish because their utility from harvest is exactly offset by their access costs. This occurs because ceasing to stock at any point would create a painful transition to a new bioeconomic equilibrium with a lower unstocked fish population. While the assumption of complete dissipation of net benefits may be strong for recreational fisheries (Horan et al. 2011), our results suggest that observing collective action investments in a common pool resource system does not necessarily mean that resource exploitation in the system is prudent or efficient.

Local stocking occurred at rates similar to our predicted optima, while stocking by the central management agency occurred at considerably higher rates (Fig. 3C). At least three mechanisms not captured by our model may contribute to high centralized stocking. First, centralized managers may consider a broader set of benefits than we included in their objective function. In particular, high fishing effort is often an important management goal in itself, despite posing challenges to fishery sustainability, because of its positive near-term economic impacts. This is commonly recognized in marine commercial fisheries 
(Stephenson and Lane 1995, Worm et al. 2009) but likely applies in recreational fisheries in places like our study region where fishing effort is an important contributor to regional economies (United States Census Bureau 2016). Second, the centralized management agency in our study region prioritizes stocking for population rehabilitation over stocking for recreation. Therefore, centralized mangers may value fish population conservation targets in ways that are unrelated to the benefits and costs to anglers. Stocking for rehabilitation may require the input of many fish to overcome ecological tipping points, positive feedbacks between fish stocks and fishing effort, or environmental stochasticity. Third, centralized managers may face significant political pressure to stock, even when doing so is not biologically or economically warranted. Future elaborations of our modeling approach could consider more nuanced models of centralized decision-making process and broader definitions of objective functions. For example, including the economic multiplier effects of fishing effort in objective functions could account for manager considerations of regional benefits of stocking. In addition, considering potential costs of stocking to biodiversity and ecosystem function could better align fisheries management with conservation objectives (Camp et al. 2017).

Our finding that incentives exist for local investment in open access common pool resources adds to a growing literature that emphasizes the benefits of polycentric governance arrangements that involve institutions at multiple scales (Schoon et al. 2015). Our analysis emphasizes that permitting and even encouraging local users to invest in improving a common pool resource, rather than limiting those powers to a centralized government, can provide benefits to both local and non-local users. This could relieve pressure on the budgets of centralized managers, thereby allowing funds to be redeployed strategically. Taken together with other arguments for local management-such as policy diversification, experimentation, responsiveness, and learning (Lorenzen and Garaway 1998, Carpenter and Brock 2004, Lebel et al. 2006, Berkes 2009, Fujitani et al. 2017) —our work helps show how local management of common pool resources can be successful, even under open access. Yet our work also demonstrates clear roles for centralized governance in enhancing social welfare, despite the social and political constraints on moving away from open access in recreational fisheries. For example, we show that in lakes where roving anglers are abundant, relying strictly on local investments yields much lower welfare than can be achieved under centralized management because local managers' investments benefit rovers only incidentally (Fig. 1B). Given real landscapes on which the abundance of local and roving resource users varies widely (e.g., Fig. 3B), intervention by a centralized manager is likely essential to optimize investments for inclusive social welfare. Similarly, centralized interventions might be necessary to counter residents' incentives to reduce the accessibility of lakes to rovers and so capture for themselves a greater share of the benefits of the fishery and any investments in it (Fig. 1), or to achieve other societal and conservation goals (Carpenter and Brock 2004). Thus, we emphasize both the potential for greater devolution of power and the necessity of continued centralized governance in spatially complex, open access common pool resources.
Responses to this article can be read online at: https://www.ecologyandsociety.org/issues/responses. php/12339

\section{Acknowledgments:}

We are grateful to the Wisconsin Department of Natural Resources for providing data used in this manuscript and to G.G. Sass for feedback on a draft of the manuscript. This work was supported by the U.S. National Science Foundation under grant number 1716066 and by the Natural Sciences and Engineering Research Council of Canada under grant numbers 475586-2015 and 402530-2011.

\section{Data Availability:}

All data and code used here will be made publicly available, upon publication of the manuscript, in the Cary Institute's figshare repository (https://caryinstitute.figshare.com/). In the interim the data and code are available from the authors upon request.

\section{LITERATURE CITED}

Anderson, L. G. 1993. Toward a complete economic theory of the utilization and management of recreational fisheries. Journal of Environmental Economics and Management 24:272-295. https:// doi.org/10.1006/jeem.1993.1018

Arlinghaus, R., J. K. Abbott, E. P. Fenichel, S. R. Carpenter, L. M. Hunt, J. Alós, T. Klefoth, S. J. Cooke, R. Hilborn, and O. P. Jensen. 2019. Opinion:Governing the recreational dimension of global fisheries. Proceedings of the National Academy of Sciences of the United States of America 116:5209-5213. https://doi. org/10.1073/pnas.1902796116

Baggio, J. A., A. J. Barnett, I. Perez-Ibarra, U. Brady, E. Ratajczyk, N. Rollins, C. Rubiños, H. C. Shin, D. J. Yu, R. Aggarwal, et al. 2016. Explaining success and failure in the commons: the configural nature of Ostrom's institutional design principles. International Journal of the Commons 10:417-439. https://doi.org/10.18352/ijc.634

Beard, T. D., S. P Cox, and S. R. Carpenter. 2003. Impacts of daily bag limit reductions on angler effort in Wisconsin walleye lakes. North American Journal of Fisheries Management 23:1283-1293. https://doi.org/10.1577/M01-227AM

Berck, P., and J. M. Perloff. 1984. An open-access fishery with rational expectations. Econometrica 52:489-506. https://doi. org/10.2307/1911500

Berkes, F. 2009. Evolution of co-management: role of knowledge generation, bridging organizations and social learning. Journal of Environmental Management 90:1692-1702. https://doi.org/10.1016/ j.jenvman.2008.12.001

Berkes, F., D. Feeny, B. J. McCay, and J. M. Acheson. 1989. The benefits of the commons. Nature 340:91-93. https://doi. org/10.1038/340091a0

Brown, G., and R. Mendelsohn. 1984. The hedonic travel cost method. Review of Economics and Statistics 66:427-433. https:// doi.org/10.2307/1924998 
Camp, E. V., S. L. Larkin, R. N. M. Ahrens, and K. Lorenzen. 2017. Trade-offs between socioeconomic and conservation management objectives in stock enhancement of marine recreational fisheries. Fisheries Research 186:446-459. https://doi. org/10.1016/j.fishres.2016.05.031

Carpenter, S. R., and W. A. Brock. 2004. Spatial complexity, resilience, and policy diversity: fishing on lake-rich landscapes. Ecology and Society 9(1):8. https://doi.org/10.5751/ES-00622-090108

Clawson, M. 1959. Methods of measuring the demand for and value of outdoor recreation. Resources for the Future Inc., Washington, D.C., USA.

Dietz, T., E. Ostrom, and P. C. Stern. 2003. The struggle to govern the commons. Science 302:1907-1912. https://doi.org/10.1126/ science. 1091015

Feeny, D., F. Berkes, B. J. McCay, and J. M. Acheson. 1990. The tragedy of the commons: twenty-two years later. Human Ecology 18:1-19. https://doi.org/10.1007/BF00889070

Fenton, R., J. A. Mathias, and G. E. E. Moodie. 1996. Recent and future demand for walleye in North America. Fisheries 21:6-12.

Fujitani, M., A. McFall, C. Randler, and R. Arlinghaus. 2017. Participatory adaptive management leads to environmental learning outcomes extending beyond the sphere of science. Science Advances 3(6):e1602516. https://doi.org/10.1126/sciadv.1602516

Gabriel, A. O., and C. Lancaster. 2004. Management issues, characteristics and effectiveness of Lake Associations and Lake Districts in Wisconsin. Lake Reservoir Management 20:27-38. https://doi.org/10.1080/07438140409354098

Gaeta, J. W., B. Beardmore, A. W. Latzka, B. Provencher, and S. R. Carpenter. 2013. Catch-and-release rates of sport fishes in northern Wisconsin from an angler diary survey. North American Journal of Fisheries Management 33:606-614. https://doi. org/10.1080/02755947.2013.785997

Gordon, H. S. 1954. The economic theory of a common-property resource: the fishery. Pages 178-203 in Classic papers in natural resource economics. Palgrave Macmillan, London, UK. https:// doi.org/10.1057/9780230523210 10

Gutiérrez, N. L., R. Hilborn, and O. Defeo. 2011. Leadership, social capital and incentives promote successful fisheries. Nature 470:386-389. https://doi.org/10.1038/nature09689

Hardin, G. 1968. The tragedy of the commons. Science 162:1243-1248. https://doi.org/10.1126/science.162.3859.1243

Horan, R. D., E. P. Fenichel, K. L. S. Drury, and D. M. Lodge. 2011. Managing ecological thresholds in coupled environmentalhuman systems. Proceedings of the National Academy of Sciences of the United States of America 108:7333-7338. https://doi. org/10.1073/pnas.1005431108

Johnson, B. M., R. Arlinghaus, and P. J. Martinez. 2009. Are we doing all we can to stem the tide of illegal fish stocking? Fisheries 34:389-394. https://doi.org/10.1577/1548-8446-34.8.389

Korth, R. M., and L. L. Klessig. 1990. Overcoming the tragedy of the commons: alternative lake management institutions at the community level. Lake and Reservoir Management 6:219-225. https://doi.org/10.1080/07438149009354712
Lebel, L., J. M. Anderies, B. Campbell, C. Folke, S. HatfieldDodds, T. P. Hughes, and J. Wilson. 2006. Governance and the capacity to manage resilience in regional social-ecological systems. Ecology and Society 11(1):19. https://doi.org/10.5751/ ES-01606-110119

Liu, J., T. Dietz, S. R. Carpenter, M. Alberti, C. Folke, E. Moran, A. N. Pell, P. Deadman, T. Kratz, J. Lubchenco, et al. 2007. Complexity of coupled human and natural systems. Science 317:1513-1516. https://doi.org/10.1126/science.1144004

Lorenzen, K., and C. J. Garaway. 1998. How predictable is the outcome of stocking? Pages 133-152 in T. Petr, editor. Inland fishery enhancements. Fisheries Technical Paper 374, FAO, Rome, Italy.

Lorenzen, K., C. J. Garaway, B. Chamsingh, and T. J. Warren. 1998. Effects of access restrictions and stocking on small water body fisheries in Laos. Journal of Fish Biology 53:345-357. https:// doi.org/10.1111/j.1095-8649.1998.tb01036.X

McConnell, K. E., and J. G. Sutinen. 1979. Bioeconomic models of marine recreational fishing. Journal of Environmental Economics and Management 6:127-139. https://doi.org/10.1016/0095-0696 (79)90025-1

McGinnis, M. D., editor. 1999. Polycentric governance and development: readings from the workshop in political theory and policy analysis. University of Michigan Press, Ann Arbor, Michigan, USA. https://doi.org/10.3998/mpub.16052

McKelvey, R. 1985. Decentralized regulation of a common property renewable resource industry with irreversible investment. Journal of Environmental Economics and Management 12:287-307. https://doi.org/10.1016/0095-0696(85) 90001-4

Moritz, M., R. Behnke, C. M. Beitl, R. B. Bird, R. M. Chiaravalloti, J. K. Clark, S. A. Crabtree, S. S. Downey, I. M. Hamilton, S. C. Phang, P. Scholte, and J. A. Wilson. 2018. Emergent sustainability in open property regimes. Proceedings of the National Academy of Sciences of the United States of America 115:12859-12867. https://doi.org/10.1073/pnas.1812028115

Ostrom, E. 1990. Governing the commons: the evolution of institutions for collective action. Cambridge University Press, Cambridge, UK.

Ostrom, E. 1998. A behavioral approach to the rational choice theory of collective action: Presidential Address, American Political Science Association, 1997. American Political Science Review 92:1-22. https://doi.org/10.2307/2585925

Post, J. R. 2013. Resilient recreational fisheries or prone to collapse? A decade of research on the science and management of recreational fisheries. Fisheries Management and Ecology 20:99-110. https://doi.org/10.1111/fme.12008

Sanchirico, J. N., and J. E. Wilen. 1999. Bioeconomics of spatial exploitation in a patchy environment. Journal of Environmental Economics and Management 37:129-150. https://doi.org/10.1006/ jeem.1998.1060

Schoon, M. L., M. D. Robards, C. L. Meek, and V. Galaz. 2015. Principle 7: Promote polycentric governance systems. Pages 226-250 in R. Biggs, M. Schlüter, and M. L. Schoon, editors. 
Principles for building resilience: sustaining ecosystem services in social-ecological systems. Cambridge University Press, Cambridge, UK.

Scott, A. 1955. The fishery: the objectives of sole ownership. Journal of Political Economy 63:116-124. https://doi. org/10.1086/257653

Smith, M. D. and J. E. Wilen. 2003. Economic impacts of marine reserves: the importance of spatial behavior. Journal of Environmental Economics and Management 46(2):183-206. https://doi.org/10.1016/S0095-0696(03)00024-X

Smith, V. L. 1968. Economics of production from natural resources. American Economic Review 58:409-431.

Stephenson, R. L., and D. E. Lane. 1995. Fisheries management sciences: a plea for conceptual change. Canadian Journal of Fisheries and Aquatic Sciences 52:2051-2056. https://doi. org/10.1139/f95-796

United States Census Bureau. 2016. National survey of fishing, hunting, and wildlife-associated recreation.

Wilen, J. E. 2018. Common property resources and the dynamics of overexploitation: the case of the North Pacific fur seal. Marine Resource Economics 33(3). https://doi.org/10.1086/698137

Worm, B., R. Hilborn, J. K. Baum, T. A. Branch, J. S. Collie, C. Costello, M. J. Fogarty, E. A. Fulton, J. A. Hutchings, S. Jennings, O. P. Jensen, H. K. Lotze, P. M. Mace, T. R. McClanahan, C. Minto, S. R. Palumbi, A. M. Parma, D. Ricard, A. A. Rosenberg, R. Watson, and D. Zeller. 2009. Rebuilding global fisheries. Science 325:578-585. https://doi.org/10.1126/science.1173146 


\section{Appendix 1 - Supplementary methods}

Investing in the commons: transient welfare creates incentives despite open access

Stocking dynamics in a fisheries model

We used a common and well-studied fish population model to illustrate the effects of stocking on fish populations:

$\frac{d X}{d t}=\dot{X}=r X\left(1-\frac{X}{k}\right)-H+S$, where $H=q E X$

where $\mathrm{X}=$ fish density, $\mathrm{H}=$ harvest, $\mathrm{r}=$ the intrinsic rate of increase, $\mathrm{k}=$ carrying capacity, $\mathrm{q}=$ catchability coefficient (proportion of the fish stock removed with one unit of effort), $\mathrm{E}=$ total fishing effort, and $\mathrm{S}=$ stocking rate. All state variables are in uppercase, and parameter values are in lowercase. This model assumes that hatcheryderived and wild fish have similar survival and value to anglers. These assumptions are supported by empirical evidence of high survival of older and larger stocked fingerlings (Santucci and Wahl 1993; Szendrey and Wahl 1996) and no significant effect of the relative abundance of wild versus hatchery derived fish on the utility anglers gain from fishing (Arlinghaus et al. 2014).

Open access angler effort from multiple user groups

We followed Horan et al. (2011) and assumed that angler utility was linear in benefits from fishing, so effort dynamics were similar to the Smith (1968) model and followed:

$\dot{E}_{i}=\delta E_{i}\left(p_{i} q X-c_{i}\right)$

Here $p_{i}=$ the marginal willingness to pay for fish harvest by angler group $i$, and $c_{i}=$ marginal cost of fishing effort for angler group $i$, which represents access costs. This effort equation follows Clark's (1990) formulation of sluggishness, with the sluggishness parameter $\delta$ controlling the rate at which effort from angler group $i$ responds to changes in the average net benefits from harvest.

We explicitly incorporated angler heterogeneity in our model by including two typical angler groups in inland recreational fisheries: lakeshore residents and roving anglers. We allowed the marginal costs of effort and the marginal willingness to pay for harvest to vary between the resident and roving angler populations. We modeled resident angler effort $\left(E_{\text {res }}\right)$ and roving angler effort $\left(E_{\text {rov }}\right)$ using Equation A1.2. Setting $\dot{E}_{i}=0$ provides two solutions at equilibrium where effort from user group $i$ is either greater than or equal to zero,

$0=\delta E_{\text {rov }}^{*}\left[p_{\text {rov }} q X^{*}-c_{\text {rov }}\right]$ if $\left\{\begin{array}{l}p_{\text {rov }} q X^{*}=c_{\text {rov }}, \\ E_{\text {rov }}^{*}=0\end{array} E_{\text {rov }}^{*}>0\right.$
$0=\delta E_{\text {res }}^{*}\left[p_{\text {res }} q X^{*}-c_{\text {res }}\right]$ if $\left\{\begin{array}{l}p_{\text {res }} q X^{*}=c_{\text {res }}, \\ E_{\text {res }}^{*}=0\end{array} E_{\text {res }}^{*}>0\right.$

where asterisks represent equilibrium values of state variables. 
We focused on the case where both resident and roving effort were present at equilibrium because our interest lies in potential investments by local resource users despite open access and because in our study region there is a long history of use by both groups. In this case, the following condition must be met,

$\frac{c_{\text {rov }}}{p_{\text {rov }} q}=\frac{c_{\text {res }}}{p_{\text {res }} q}=X^{*} \rightarrow p_{\text {rov }}=\frac{c_{\text {rov }} p_{\text {res }}}{c_{\text {res }}}$

Thus, the higher marginal cost of effort for rovers than for residents that characterizes this system implies that the rovers' marginal willingness to pay for harvest must also be higher with $p_{\text {rov }}=\frac{c_{\text {rov }} p_{\text {res }}}{c_{\text {res }}}$, assuming catchability of the two groups to be approximately equivalent. Therefore, we assumed that the higher access costs that rovers face, compared to residents, are balanced by higher value of harvest. This assumption was supported by valuations of roving and resident angler willingness to pay per walleye in our study region; on average marginal willingness to pay per walleye, calculated using the travel cost method, was 54\% higher for non-waterfront property owners than for waterfront property owners (Murdock 2001). We also assumed that there was high latent resident and roving fishing effort in the fishery such that the number of potential resident and roving anglers never limited realized fishing effort (Hunt et al. 2011; Wilson et al. 2016).

Formulating the model with increasing (rather than constant) marginal costs of effort changes the conditions under which both resident and rover effort are present at equilibrium. We consider this alternative model formulation, and its implications for our key results, in Appendix 5.

\section{Optimal stocking decisions by local and centralized managers}

Our model considers stocking by either a local collective action organization of lakeshore residents, or by a centralized government agency. We defined each manager's objective to be finding the stocking rates through time that maximize the present value of net benefits (PVNB) to anglers. The local manager's objective function considers only the lakeshore resident anglers, while the centralized manager considers both the resident and roving anglers. Specifically,

$\begin{array}{ll}P V N B_{\text {Local mGMT }}=\int_{t=0}^{\infty} e^{-\rho t}\left(p_{\text {res }} q E_{\text {res }} X-c_{\text {res }} E_{\text {res }}-\gamma S^{2}\right) d t & \text { Eq.A1.6 } \\ P V N B_{\text {Central mGMT }}=\int_{t=0}^{\infty} e^{-\rho t}\left(p_{\text {res }} q E_{\text {res }} X-c_{\text {res }} E_{\text {res }}+p_{\text {rov }} q E_{\text {rov }} X-c_{\text {rov }} E_{\text {rov }}-\gamma S^{2}\right) d t & \text { Eq.A1.7 }\end{array}$

where, $\rho=$ the discount rate, $\gamma$ is proportional to the marginal cost of stocking, and the terms in parentheses represent the net benefits of harvest for anglers less the cost of stocking. The integral of net benefits of harvest adds up the net benefits over time, with future benefits weighted less through the discount term $e^{-\rho t}$. We modeled the cost of stocking as a non-linear function to represent the increased production costs associated with the need to increase the production capacity of hatcheries or buying hatchery fish from exogenous sources at high stocking rates (Askey et al. 2013).

We solved for the optimal stocking rate over time that maximized the local or centralized manager's objective function, using numerical solutions of the constrained nonlinear multivariable functions. We used the fmincon function in Matlab to compute 
the optimal stocking rates over a 100-year planning horizon. The default initial conditions were $E_{r e s}=1, E_{r o v}=1$, and $X=24$ (carrying capacity). However, to demonstrate investment incentives in the least conducive conditions we also initialized the model from the no-stocking open access equilibrium. The equilibrium conditions for fish biomass and total effort were given by:

$X^{*}=d q$

$E_{\text {Total }}^{*}=\frac{(-b d+q r)}{q^{2}}$

where $b=\frac{r}{k}$ and $d=\frac{c_{i}}{p_{i}}$

We used the mean of the optimal stocking rate after the first 50 years to represent optimal stocking in equilibrium because equilibrium was always reached after this time frame. Although we derived the necessary optimal conditions using calculus of variations and the maximum principle, we relied on numerical solutions because the Hessian matrix, which must be concave or quasi-concave to satisfy sufficiency conditions for an optimal solution (Arrow and Enthoven 1961), was indefinite (Appendix 2). However, both methods led to similar results (Ziegler 2018).

To compare social welfare under centralized and local management we used the combined present value of net benefits of each angler group less the cost of stocking (Equation A1.6 and A1.7). Because PVNB is an integral of the trajectory of the system over time it is dependent on initial conditions of the state variables; therefore, we present the results over a range of the proportion of resident anglers in the angling pool at equilibrium, which is determined by the initial abundance of resident versus roving anglers (Fig. A1.1).

\section{Model parameterization}

For numerical solutions, we parameterized the model to reflect the recreational fishery for walleye (Sander vitreus) in northern Wisconsin, USA. We sought to use the most recent or most comprehensive data available, and converted all dollar amounts to 2016 dollars. Parameter values and associated references are summarized in Table A1.1.

We used empirically derived estimates of walleye intrinsic growth rate and carrying capacity (Hunt et al. 2011). For default values we choose the lower end of intrinsic rate of increase and higher end of carrying capacity reported in Hunt et al. (2011) but examine their full gradient in Fig. A1.2. We followed the approach of Hunt et al. (2011) and calculated area specific catchability using the maximum mean yearly walleye catch rate ( 1.53 walleye per hour) reported for our study region, assuming that catchability does not vary with density (Hansen et al. 2005). We converted catch rate to mean yearly catch rate per trip ( 0.84 walleye per trip) using data on the average time an angler spent fishing, the number of walleye anglers, and the total number of trips walleye anglers took (McClanahan and Hansen 2000).

We set $\delta$, the sluggishness of fishing effort to average net benefits of harvest, equal to 0.01 . Setting $\delta$ to a low value like this speeds convergence to equilibrium, and 
sensitivity analyses varying $\delta$ over the range from 0 to 1 indicated that the correlation between observed and predicted stocking rates was insensitive to $\delta$ (Fuller et al. 2013, Ziegler 2019).

The $\gamma$ parameter describes how the total cost of stocking, $C$, varies with the stocking density, $S$ ( $C=\gamma S^{2}$; Eq. A1.6 and A1.7). We calculated a value for $\gamma$ using data on the average price per stocked fish $\bar{z}_{a}$, average stocking density $\bar{S}_{a}$, and rate of survival to adulthood $m_{a}$ for fish stocked at small fingerling, large fingerling, and extended growth fingerling size classes $a$ (Wisconsin Dept. of Natural Resources 1999, Kampa and Hatzenbeler 2009). First, we calculated the density of stocked fish that survive to adulthood, $\tilde{S}_{a}=m_{a} \bar{S}_{a}$ (fish ha- $\mathrm{y}^{-1}$ ). The size of small and large fingerlings stocked in Wisconsin (median length of $41 \mathrm{~mm}$ and $178 \mathrm{~mm}$, respectively) corresponded to $m_{\text {small fingerling }}=0.01$ and $m_{\text {large fingerling }}=0.21$ in Kampa and Hatzenbeler (2009). For extended growth fingerlings, which are stocked at a catchable size and immediately enter the fishery, we assumed $m_{\text {extended growth }}=1$. Next, we calculated the expenditures on stocking, $C_{a}=\bar{z}_{a} \bar{S}_{a}\left(\$ \mathrm{ha}^{-1} \mathrm{y}^{-1}\right)$. With these estimates we solved for a value of $\gamma$ for each size class, $\gamma=C_{a} / \tilde{S}_{a}{ }^{2}$, and then took the average across the size classes $\left(=1.74 \$\right.$ ha $y$ fish $\left.^{-2}\right)$ to use as the default value of $\gamma$ in our simulations.

\section{Comparison to empirical data}

We examined whether model-predicted rates of local and centralized stocking, and model-predicted fish abundance, were similar to observed data from 46 lakes in Vilas and Oneida counties, northern Wisconsin. For each of lake we parameterized a version of the model that included lake-specific estimates of resident and roving angler effort, roving angler access costs and willingness to pay for harvest, and catchability.

We estimated resident and roving angler effort from a large creel survey study in the region (Table A1.1). Creel clerks surveyed angler groups on lakes and recorded if they used the boat landing to launch their boat (roving anglers) or if they came from a lakeshore residence (resident anglers). The number of angler groups interviewed per lake ranged from 79 to 5,548 with a median of 1,108. Total angler effort in our empirical data set ranged from 2 to 35 angler trips per hectare per year (Fig. A1.3), and residents accounted for $0.1 \%$ to $92 \%$ of that effort (Table A1.1).

We calculated per-trip costs of roving anglers using the round-trip distance of a lake to the nearest urban center, the average operational cost of a sport utility vehicle in the USA (\$0.11 USD per km, American Automobile Association 2016), and the average operating cost of a boat for a freshwater angler in the USA (U.S. Census Bureau 2016). We then estimated the value of fish harvest for roving anglers using Equation A1.5.

We calculated lake specific walleye catchability using walleye harvest by both angler groups, effort by both angler groups, and walleye populations estimates for each lake (Table A1.1). For the three lakes where we did not have walleye population estimates we used the median catchability across the other 43 lakes.

We obtained data on stocking rates and walleye densities from the Wisconsin Department of Natural Resources, including all records of government and local organization stocking of walleye fingerlings; angler effort; and walleye population estimates in public access lakes in our study region (DNR 2019, see Fig. A1.3 for 
distributions of these data among our lakes). Data on stocking rates and walleye densities were divided by lake area to match the areal density units of the model. Our study lakes ranged in area from 46 to 1626 ha (median 190 ha).

We tested if observed and model predicted optimal stocking rates and walleye densities were similar for both local and centralized management. We used paired ttests to determine if the mean of differences in observed and predicted state variables were significantly different from zero for both local and centralized management.

\section{Literature cited}

American Automobile Association. 2016. AAA's Your Driving Costs [WWW Document]. https://exchange.aaa.com/automotive/drivingcosts/\#.XV_v_pNKhTY

Arlinghaus, R., B. Beardmore, C. Riepe, J. Meyerhoff, and T. Pagel. 2014. Species specific preferences of German recreational anglers for freshwater fishing experiences, with emphasis on the intrinsic utilities of fish stocking and wild fishes. Journal of Fish Biology 85:1843-1867.

Arrow, K.J., and A.C. Enthoven. 1961. Quasi-concave programming. Econometrica: Journal of the Econometric Society 779-800.

Askey, P.J., E.A. Parkinson, and J.R. Post, J.R. 2013. Linking Fish and Angler Dynamics to Assess Stocking Strategies for Hatchery-Dependent, Open-Access Recreational Fisheries. North American Journal of Fisheries Management 33:557-568.

Clark, C.W. 1990. Mathematical bioeconomics: the optimal management of renewable resources. Wiley-Interscience, Hoboken, N.J.

DNR. 1999. An evaluation of stocking strategies in Wisconsin with an analysis of projected stocking needs. Wisconsin Department of Natural Resources, Bureau of Fisheries Management and Habitat Protection. https://dnr.wisconsin.gov/sites/default/files/topic/Fishing/Pubs_stockrep.pdf

DNR. 2019. Wisconsin Department of Natural Resources Fisheries Management Database.

Fenichel, E.P., R.D. Horan, and J.R. Bence. 2010. Indirect management of invasive species through bio-controls: A bioeconomic model of salmon and alewife in Lake Michigan. Resource and Energy Economics 32:500-518.

Hansen, M.J., T.D. Beard, and S.W. Hewett. 2005. Effect of Measurement Error on Tests of Density Dependence of Catchability for Walleyes in Northern Wisconsin Angling and Spearing Fisheries. North American Journal of Fisheries Management 25:1010-1015.

Horan, R.D., E.P. Fenichel, K.L.S. Drury, and D.M. Lodge. 2011. Managing ecological thresholds in coupled environmental-human systems. Proceedings of the National Academy of Sciences of the United States of America 108:7333-7338.

Hunt, L.M., R. Arlinghaus, N. Lester, and R. Kushneriuk. 2011. The effects of regional angling effort, angler behavior, and harvesting efficiency on landscape patterns of overfishing. Ecological Applications 21:2555-2575.

Johnson, R.J., M.H. Ranson, E.Y. Besedin and E.C. Helm. 2006. What Determines Willingness to Pay per Fish? A Meta-Analysis of Recreational Fishing Values. Marine Resource Economics 21:1-32.

Kampa, J.M., and G.R. Hatzenbeler. 2009. Survival and growth of walleye fingerlings stocked at two sizes in 24 Wisconsin lakes. North American Journal of Fisheries Management 29:996-1000. 
McClanahan, D., and M. Hansen. 2000. A Statewide Mail Survey to Estimate 2000-2001 Angler Catch, Harvest, and Effort in Wisconsin. Fisheries Management Report No. 151. Wiscosin Department of Natural Resources.

Murdock, J. 2001. Valuing Recreational Fishing Opportunities While Catching Unobserved Characteristics. Yale University, New Haven, CT.

Santucci, V.J. and D.H. Wahl. 1993. Factors Influencing Survival and Growth of Stocked Walleye (Stizostedion vitreum) in a Centrarchid-Dominated Impoundment. Canadian Journal of Fisheries and Aquatic Sciences 50:1548-1558.

Smith, V.L. 1968. Economics of Production from Natural Resources. American Economic Review 58:409-431.

Szendrey, T.A. and D.H. Wahl. 1996. Size-Specific Survival and Growth of Stocked Muskellunge: Effects of Predation and Prey Availability. North American Journal of Fisheries Management 16:395-402.

U.S. Census Bureau. 2016. National Survey of Fishing, Hunting, and Wildlife-Associated Recreation.

Wilson, K.L., A. Cantin, H.G.M Ward, E.R. Newton, J.A. Mee, D.A. Varkey, E.A. Parkinson, and J.R. Post. 2016. Supply-demand equilibria and the size-number trade-off in spatially structured recreational fisheries. Ecological Applications 26:1086-1097.

Ziegler, J.P. 2019. Social-ecological interactions in inland recreational fisheries. Doctoral thesis. McGill University. 
Table A1.1. Parameter values for bio-economic stocking model. Prices in 2016 U.S. dollars.

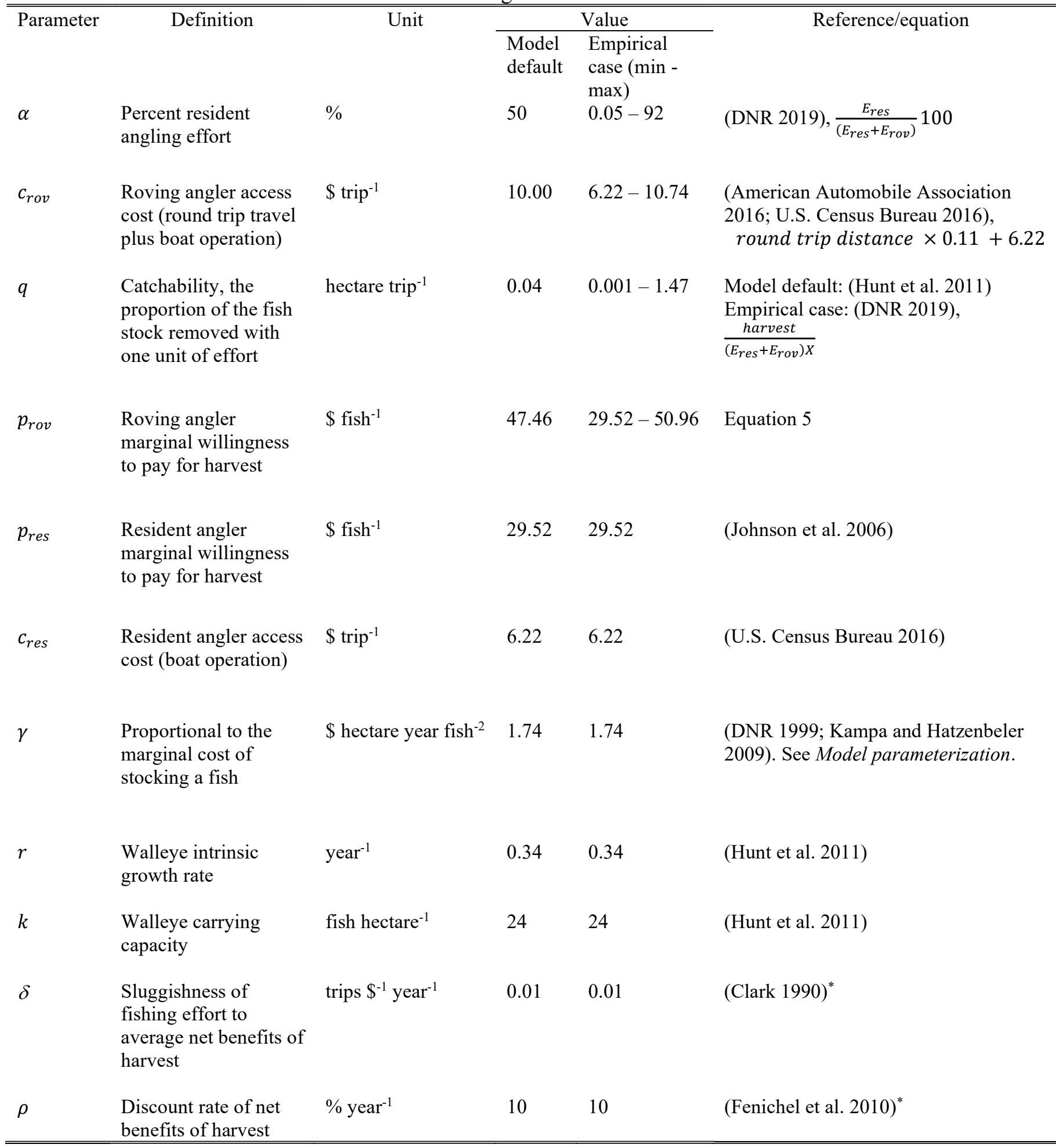

\footnotetext{
${ }^{*}$ Does not provide an empirical estimate of model parameter
} 


\section{Figure A1.1}

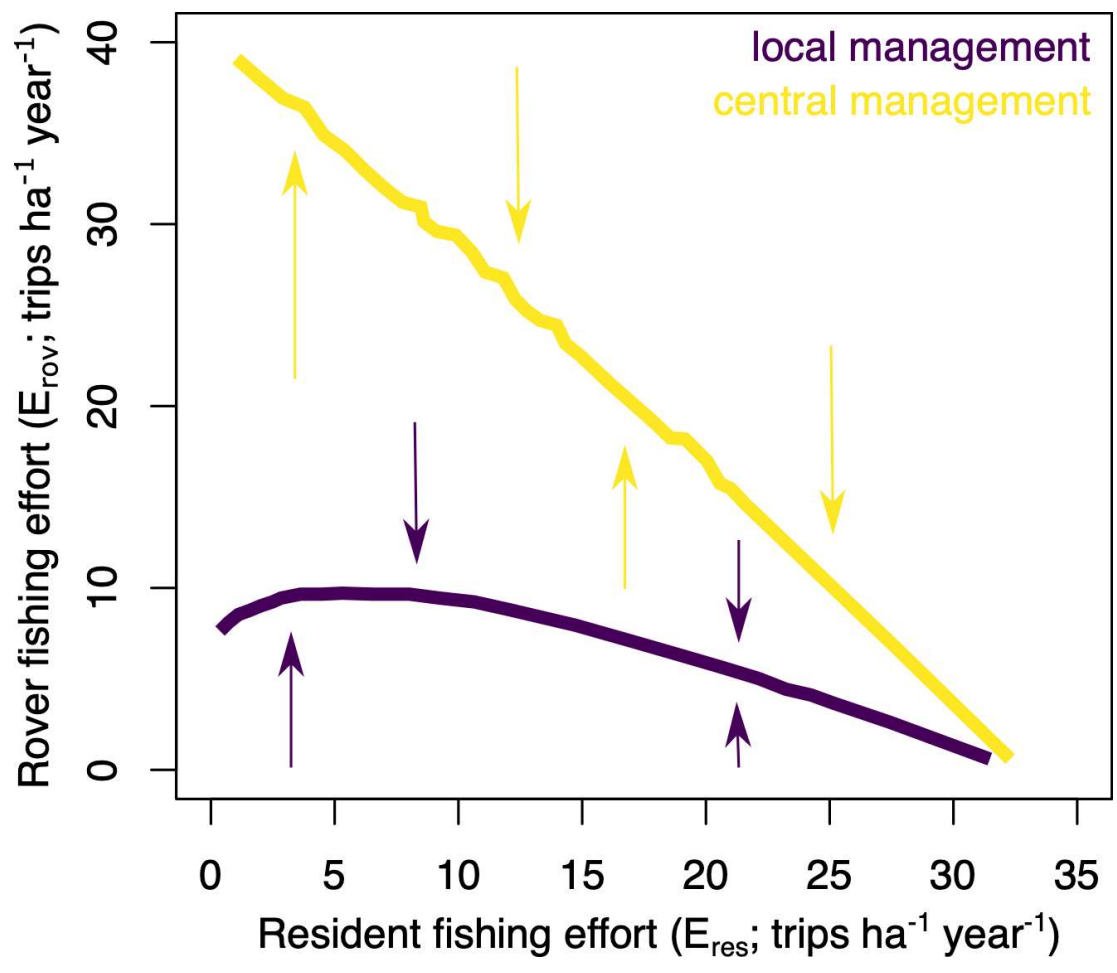

Figure A1.1. Phase plane of equilibrium fishing effort by resident and roving anglers, under local and centralized management. High initial fishing effort from either angler group confers an advantage for equilibrium fishing effort of that group because it reduces catch benefits for the alternative angler group, attracting less of their effort. 
Figure A1.2

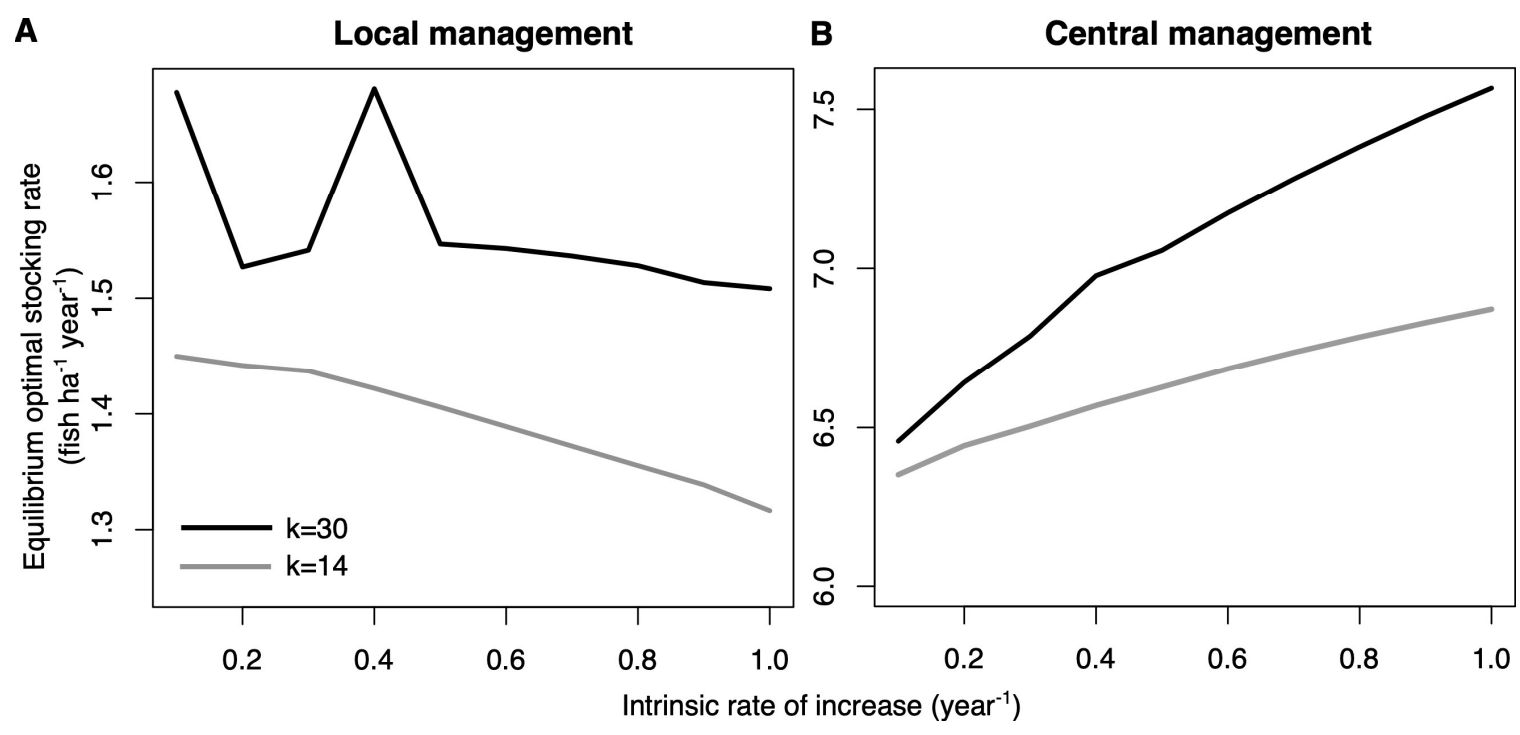

Figure A1.2. Optimal stocking rates for high (black) and low (gray) carrying capacity as a function of the intrinsic rate of increase of the fish population when stocking is conducted by (A) local and (B) centralized management. 
Figure A1.3

Local Central
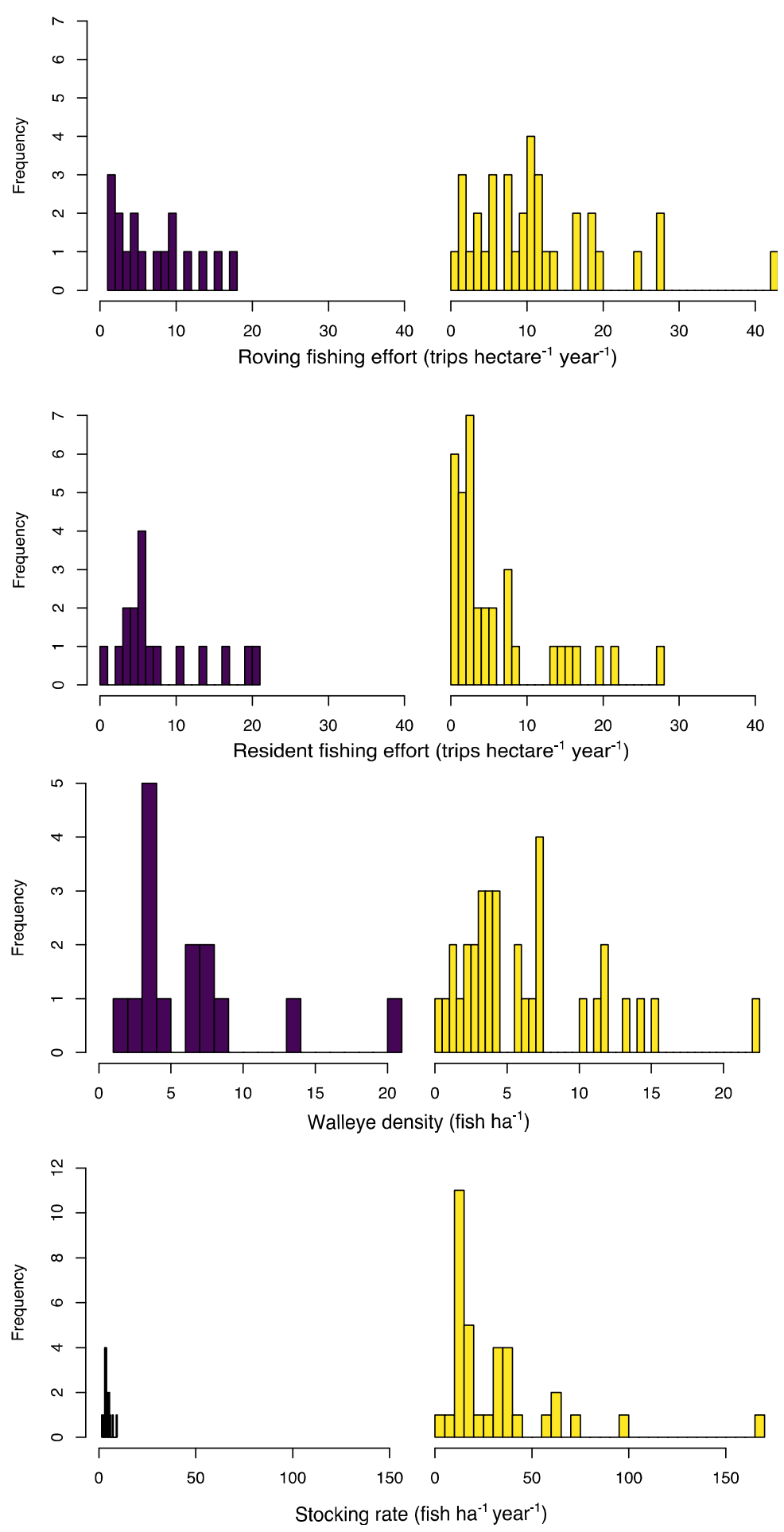

Figure A1.3. Frequency distributions of roving and resident angler effort, walleye population densities, and local and centralized stocking rates of walleye in 46 lakes in Vilas and Oneida counties, northern Wisconsin, USA. Data from Wisconsin Department of Natural Resources (DNR 2019). 


\section{Appendix 2 - Optimal control theory solution for optimal stocking rate}

Investing in the commons: transient welfare creates incentives despite open access

Optimal control theory and the maximum principal provide the necessary optimal stocking rate over time that maximizes a defined objective function (Clark 1990). The optimal stocking rate is expressed as a function of shadow prices $\left(\mu_{i}\right)$ that are determined from constructing a Hamiltonian $(\mathcal{H})$ of the optimal control problem:

Government Hamiltonian:

$$
\begin{aligned}
& \mathcal{H}=e^{-\rho t}\left(p_{R E S} q E_{R E S} X-c_{R E S} E_{R E S}+p_{R O V} q E_{R O V} X-c_{R O V} E_{R O V}-\gamma S^{2}\right) \\
& +\lambda_{1}\left(r X-b X^{2}-q E X+S\right) \\
& +\lambda_{2}\left(\delta E_{R E S}\left[p_{R E S} q X-c_{R E S}\right]\right)+\lambda_{3}\left(\delta E_{R O V}\left[p_{R O V} q X-c_{R O V}\right]\right)
\end{aligned}
$$

Lake association Hamiltonian:

$$
\begin{aligned}
& \mathcal{H}=e^{-\rho t}\left(p_{R E S} q E_{R E S} X-c_{R E S} E_{R E S}-\gamma S^{2}\right) \\
& +\lambda_{1}\left(r X-b X^{2}-q E X+S\right)+\lambda_{2}\left(\delta E_{R E S}\left[p_{R E S} q X-c_{R E S}\right]\right) \\
& +\lambda_{3}\left(\delta E_{R O V}\left[p_{R O V} q X-c_{R O V}\right]\right)
\end{aligned}
$$

The current value Hamiltonian $(\widetilde{\mathcal{H}})$ equals $e^{\rho t}(\mathcal{H})$ and the current shadow price for state variable $l\left(\mu_{l}\right)$ equals $e^{\rho t}\left(\lambda_{l}\right)$. The maximum principle provides the differential equations of the current value shadow prices and the optimal stocking rate:

\section{Current shadow prices}

Lake association:

$$
\begin{aligned}
\dot{\mu_{1}}= & -p_{R E S} q E_{R E S}-2 \gamma S\left(r-2 b X-q\left(E_{R O V}+E_{R E S}\right)-\rho\right) \\
& -\delta q\left(\mu_{2} p_{R E S} E_{R E S}+\mu_{3} p_{R O V} E_{R O V}\right)
\end{aligned}
$$

Government:

$$
\begin{aligned}
\dot{\mu_{1}}= & -q\left(p_{R O V} E_{R O V}+p_{R E S} E_{R E S}\right)-2 \gamma S\left(r-2 b X-q\left(E_{R O V}+E_{R E S}\right)-\rho\right) \\
& -\delta q\left(\mu_{2} p_{R E S} E_{R E S}+\mu_{3} p_{R O V} E_{R O V}\right) \\
\dot{\mu_{2}=} & \mu_{2}\left(\rho-\delta p_{R E S} q X+\delta c_{R E S}\right)+q X\left(2 \gamma S-p_{R E S}\right)+c_{R E S}
\end{aligned}
$$

Lake association:

$\dot{\mu_{3}}=2 \gamma S q X-\mu_{3}\left(\delta p_{R O V} q X-\delta c_{R O V}-\rho\right)$

Government:

$$
\dot{\mu_{3}}=\mu_{3}\left(\rho-\delta p_{R O V} q X+\delta c_{R O V}\right)+q X\left(2 \gamma S-p_{R O V}\right)+c_{R O V}
$$

\section{Optimal Stocking}

By Equations A2.1 and A2.2, $\frac{d \widetilde{\mathcal{H}}}{d S}=-2 S \gamma+\mu_{1}=0$, therefore, $\mu_{1}=2 S \gamma$. Taking the derivative of both sides of this equation with respect to time and solving for $\dot{S}$ gives,

$$
\dot{S}=\frac{\dot{\mu}}{2 \gamma}
$$


By the Arrow principle, the necessary conditions above are sufficient if $\mathcal{H}$ evaluated at $\mathrm{S}^{*}$ is concave with respect to all state variables over the planning horizon. Concavity of the Hamiltonian is determined by the properties of its Hessian matrix. However, our Hessian matrices are indeterminate, so no conclusion about the concavity of the function can be made.

\section{Literature cited}

Clark, C.W. 1990. Mathematical bioeconomics: the optimal management of renewable resources. Wiley-Interscience, Hoboken, N.J. 


\section{Appendix 3 - Net benefits per unit fishing effort for resident and roving anglers when roving anglers have higher travel costs than residents}

Investing in the commons: transient welfare creates incentives despite open access

The net benefits of harvest per unit of fishing effort for an angler is:

$N B_{i}=p_{i} q X-c_{i}$

Where $N B=$ the net benefits of harvest per unit of effort from user group $i, p=$ marginal willingness to pay for harvest for user group $i, q=$ catchability coefficient, $X=$ fish stock density, and $c=$ marginal cost of fishing effort for user group $i$.

Substituting Equation A1.5 into Equation A3.1 demonstrates open-access "rent" dissipation at equilibrium because the marginal net benefits for each user group are equal to 0 ,

$N B_{r e s}^{*}=p_{\text {res }} q X^{*}-c_{\text {res }}=p_{\text {res }} q \frac{c_{\text {res }}}{p_{\text {res }} q}-c_{\text {res }}=0$

$N B_{\text {rov }}^{*}=p_{\text {rov }} q X^{*}-c_{\text {rov }}=\frac{c_{\text {rov }} p_{\text {res }}}{c_{\text {res }}} q \frac{c_{\text {res }}}{p_{\text {res }} q}-c_{\text {rov }}=0$

However, when the fish stock is not at equilibrium and is at density $X$, the marginal net benefits of resident anglers is less than roving anglers when $c_{\text {res }}<c_{\text {rov }}$ :

$N B_{\text {res }}<N B_{\text {rov }}$,

$p_{\text {res }} q X-c_{\text {res }}<p_{\text {rov }} q X-c_{\text {rov }}$,

$p_{\text {res }} q X-c_{\text {res }}<\frac{c_{\text {rov }} p_{\text {res }}}{c_{\text {res }}} q X-c_{\text {rov }}$,

$p_{\text {res }} q X-c_{\text {res }}+c_{\text {rov }}<\frac{c_{\text {rov }}}{c_{\text {res }}} p_{\text {res }} q X$,

$1-\frac{c_{\text {res }}+c_{\text {rov }}}{p_{\text {res }} q X}<\frac{c_{\text {rov }}}{c_{\text {res }}}$

$c_{\text {res }}-\frac{2 c_{\text {res }}+c_{\text {res }} c_{\text {rov }}}{p_{\text {res }} q X}<c_{\text {rov }}$,

$-\frac{2 c_{\text {re }}+c_{\text {res }} c_{\text {rov }}}{p_{\text {res }} q X}<c_{\text {rov }}-c_{\text {res }}$,

is true given $c_{\text {res }}<c_{\text {rov }}$ (i.e. $c_{\text {rov }}-c_{\text {res }}>1$ ) and $X \neq 0$. 


\section{Appendix 4 - Supplementary results}

Investing in the commons: transient welfare creates incentives despite open access

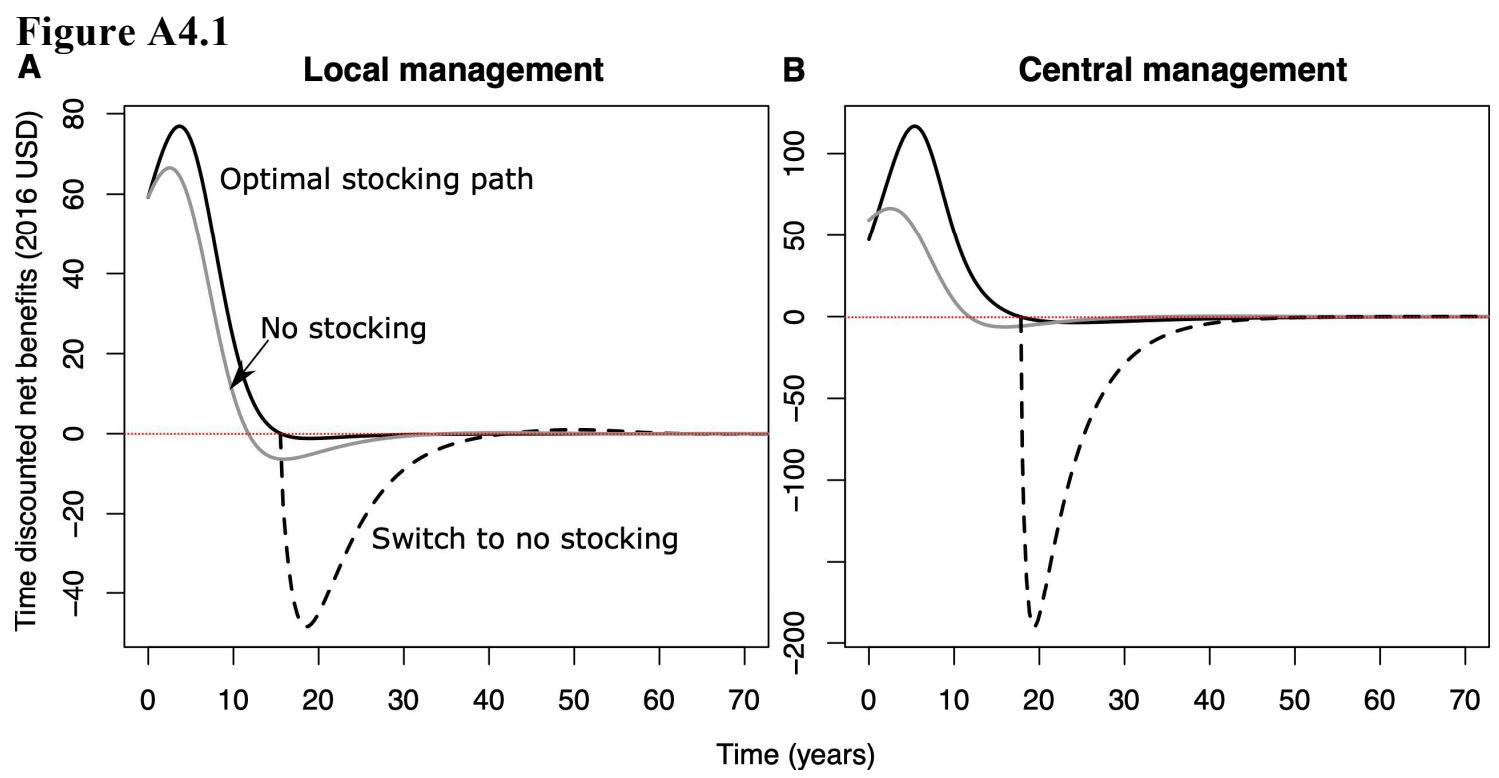

Figure A4.1. Comparison of present value of net benefits (PVNB) over time of (A) local and (B) centralized management when no stocking (gray) and optimal stocking (black) are followed. Stocking decisions are initialized from pristine conditions when there is little fishing pressure ( 2 angling trips per year) and the fish stock is at carrying capacity (24 fish per hectare). Near equilibrium the PVNB in the no stocking scenario is slightly higher than in the optimal stocking scenario (only visible in B). At this point (and all others) switching from the optimal stocking path to no stocking (dashed line) results in PVNB becoming more negative as effort drawn into the system from stocking leaves and anglers realize a loss in harvest benefits. Note different y-axis scales. 


\section{Appendix 5 - Alternative model formulation with increasing marginal costs of effort}

Investing in the commons: transient welfare creates incentives despite open access

Consider an alternative formulation of our model (Appendix 1) in which the marginal cost of effort is increasing. Now the current-period average net benefits are equal to:

$N B_{i}=p_{i} q X-c_{i} E_{i}$,

The modified versions of Eq. S3-4 then become

$0=\delta E_{\text {rov }}^{*}\left[p_{\text {rov }} q X^{*}-c_{\text {rov }} E_{\text {rov }}^{*}\right]$ if $\left\{\begin{array}{c}p_{\text {rov }} q X^{*}=c_{\text {rov }} E_{\text {rov }}^{*}, E_{\text {rov }}^{*}>0, \\ E_{\text {rov }}^{*}=0\end{array}\right.$
$0=\delta E_{\text {res }}^{*}\left[p_{\text {res }} q X^{*}-c_{\text {res }} E_{\text {res }}^{*}\right]$ if $\left\{\begin{array}{c}p_{\text {res }} q X^{*}=c_{\text {res }} E_{\text {res }}^{*}, E_{\text {res }}^{*}>0 . \\ E_{\text {res }}^{*}=0\end{array}\right.$

From these new equilibrium equations, an alternative condition will emerge (compare to Eq.A1.5):

$\frac{c_{\text {rov }} E_{\text {rov }}^{*}}{p_{\text {rov }} q}=\frac{c_{\text {res }} E_{\text {res }}^{*}}{p_{\text {res }} q}=X^{*} \rightarrow \alpha^{*}=\frac{E_{\text {res }}^{*}}{E_{\text {rov }}^{*}}=\frac{c_{\text {rov }} / p_{\text {rov }}}{c_{\text {res }} / p_{\text {res }}}$

The alternative condition implies that the ratio of equilibrium effort levels of the two angler groups is inversely related to the ratios of their cost and benefit parameters.

Exploring this model of increasing marginal cost we find that three of our four key model results hold, as detailed below.

Key Result 1: "Local users had clear incentives to invest in the fishery despite open access". This holds as shown in Figure A5.1, which compares time discounted net benefits from stocking to not stocking in a system where there are increasing marginal cost of angling effort. The new results show gains for both local and centralized managers. The figure is similar to Figure 2 in the main text, where switching to no stocking after the welfare dissipating equilibrium is reached leads to large losses as the system must transition to a new equilibrium with a lower level of the resource stock. 


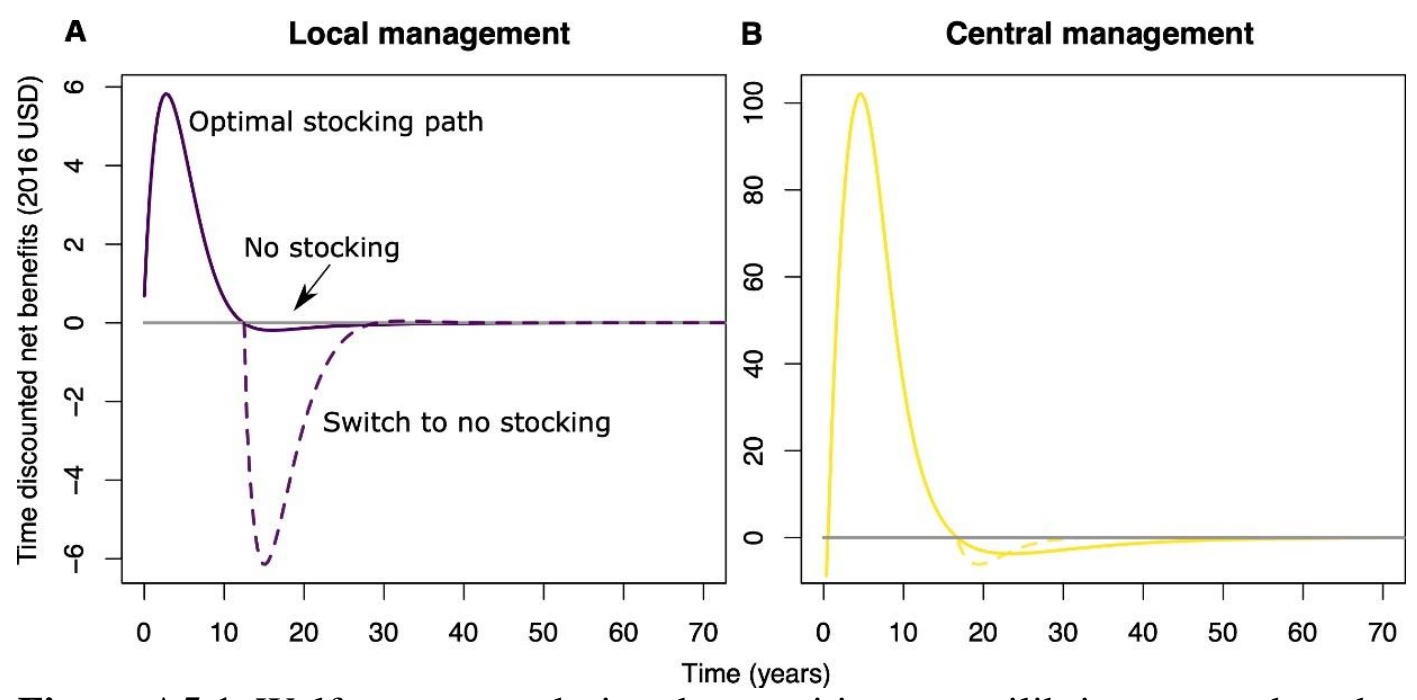

Figure A5.1. Welfare accrues during the transition to equilibrium, even though rents are dissipated at equilibrium, under (A) local management and (B) centralized management. Starting from the no-stocking open access equilibrium, we considered three scenarios. First, if there is no stocking (grey line), the system remains at the open access equilibrium and time discounted net benefits are zero over the entire time horizon. Second, if stocking follows the welfare-maximizing optimal path (solid line), welfare is initially negative because costs but not benefits of stocking have been realized; becomes positive and then negative again as effort responds sluggishly to changes in the fishery; and finally reequilibrates at the open access equilibrium. Third, switching from the optimal stocking path to no stocking (dashed line) does not yield gains in welfare, regardless of the time point at which the switch is made, because ceasing to stock produces negative net benefits for anglers as effort declines and the system transitions to equilibrium.

Key Result 2: The equilibrium effort levels of both user groups depend on the initial conditions. This result does not hold given the new equilibrium condition on effort is only a function of the ratio of economic parameters, i.e.

$\alpha^{*}=\frac{E_{\text {res }}^{*}}{E_{\text {rov }}^{*}}=\frac{c_{\text {rov }} / p_{\text {rov }}}{c_{\text {res }} / p_{\text {res }}}$

The new condition specifies that with a greater steepness in the slope of the marginal cost function for a particular angler group, there will be a smaller fraction of that angler group present at equilibrium, which seems intuitive. However, it also seems intuitive that lakes starting out with high roving angler effort will attract less lakeside homeowners with interest in recreational angling. Therefore, it is not clear which model assumption is superior and whether equilibrium conditions in recreational fisheries depend on initial conditions, or not, is an empirical question.

Key Result 3: For local managers stocking is positively related to the fraction of resident anglers at equilibrium. This result holds as shown in Figure A5.2. To explore this result, we run the model over a range of values of the $c_{\text {rov }}$ parameter thus creating variation in $\alpha^{*}$. The results can be compared to Figure 1 in the main text. 

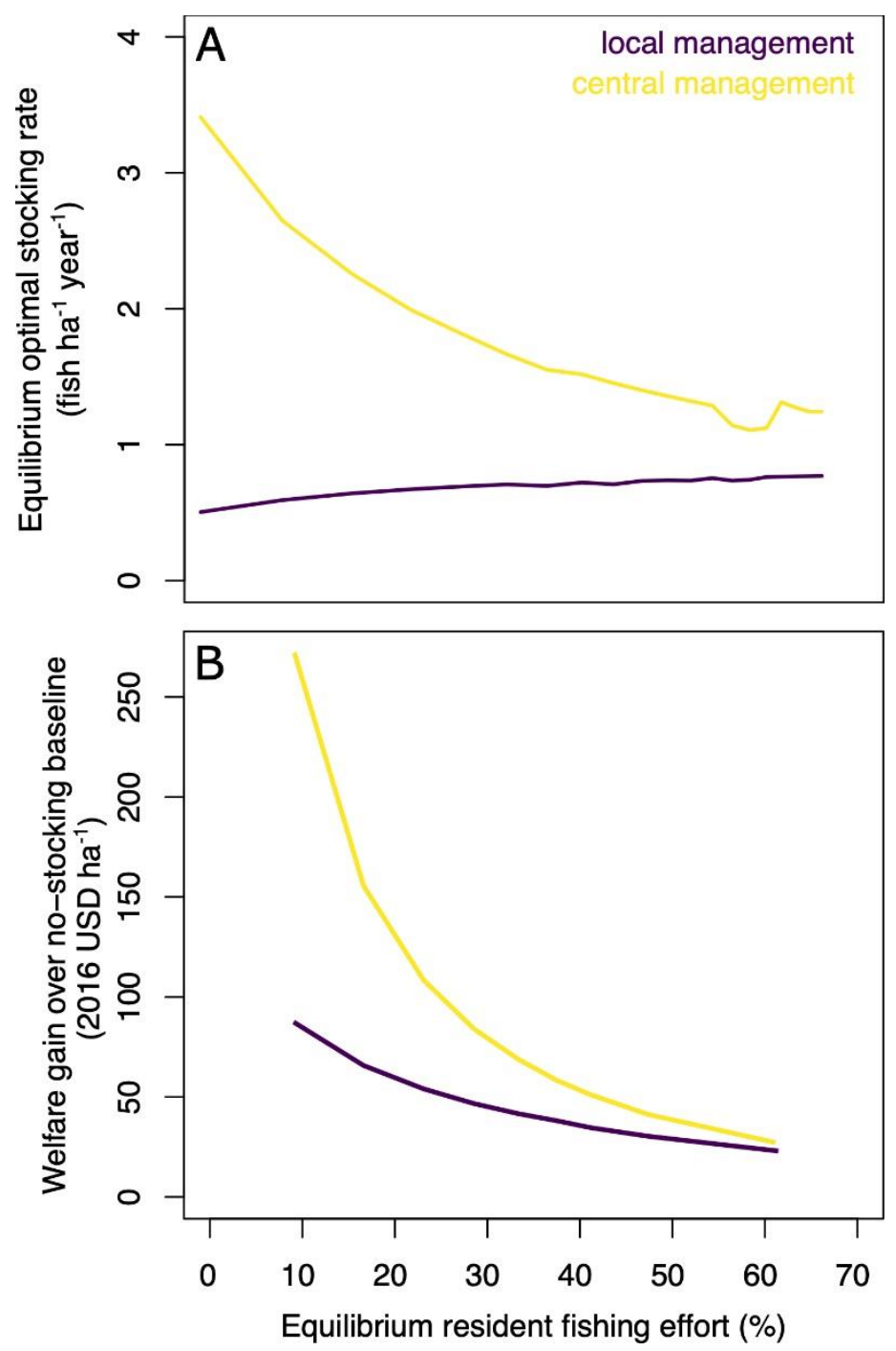

Figure A5.2. (A) Optimal stocking rate and (B) welfare gain (time discounted net benefits) from stocking relative to a no-stocking baseline, under local management by a collective action organization of lakeshore residents or centralized management by a government agency. The optimal investment and the resulting welfare gain depend on the proportion of total equilibrium angling effort that is comprised of resident anglers ( $\mathrm{x}$-axis).

Key Result 4: Welfare gains are greatest for residents when they comprise the most equilibrium angling effort. This result is also shown in Figure A5.2, which can be compared to Figure 1 in the main text. 